\title{
XPO1en bidezko garraio nukleozitoplasmikoa: oinarrizko mekanismoak eta hurbilketa esperimentalak
}

\author{
(XPO1-mediated nucleocytoplasmic transport: basic mechanisms \\ and experimental approaches)
}

\author{
Maria Sendino $^{1}$, Anne Olazabal-Herrero ${ }^{1,2}$, Jose Antonio Rodriguez $z^{1}$, \\ Miren Josu Omaetxebarria ${ }^{3 *}$ \\ ${ }^{1}$ Genetika, Antropologia Fisikoa eta Animalien Fisiologia Saila (UPV/EHU) \\ ${ }^{2}$ Department of Pediatrics-Hematology/Oncology. Yale University School of Medicine \\ ${ }^{3}$ Biokimika eta Biologia Molekularra Saila (UPV/EHU)
}

\begin{abstract}
LABURPENA: Zelula eukariotoen nukleoa inguratzen duen mintzak zelularen bi konpartimentu nagusien (nukleoaren eta zitoplasmaren) arteko banaketa fisikoa ezartzen du. Bi konpartimentu horien arteko komunikazioa, etengabea izateaz gain, ezinbestekoa da zelularen homeostasia mantentzeko. Komunikazio hori, nukleoaren mintzean zehar noranzko bietan izaten den molekula-mugikortasunak egikaritzen du. Komunikazio horretan funtsezkoa den proteina bat dugu mintzagai honako artikuluan: XPO1 izeneko proteina, alegia. Nukleotik zitoplasmarako garraioan jarduten duen esportazio-hartzaile nagusia da XPO1, eta ehunka proteina eta zenbait RNA molekula esportatzen ditu. Artikulu honetan, garraio nukleozitoplasmikoaren mekanismo molekularrak deskribatzeaz gain, XPO1 esportazio-hartzailean zentratu gara, eta haren funtzioa aztertzeko erabili ohi diren hurbilketa esperimentalak jaso ditugu. Azken horien adibide gisa, berriki deskribatutako USP12/WDR20 konplexuaren kasua [1] aztertu dugu.
\end{abstract}

HITZ GAKOAK: garraio nukleozitoplasmikoa, XPO1, NES, WDR20, USP12.

\begin{abstract}
The nuclear envelope, a double membrane that encloses the nucleus of eukaryotic cells, establishes a physical separation between the two main cellular compartments: the nucleus and the cytoplasm. Continuous communication between these compartments is crucial for the maintenance of cellular homeostasis. This communication relies on the bidirectional transport of macromolecules across the nuclear envelope. We focus here on a protein, called XPO1, which plays a key role in nucleocytoplasmic transport. XPO1 is the main receptor that mediates the export of hundreds of proteins and several RNA molecules from the nucleus to the cytoplasm. In this article we first review the molecular mechanisms that underlie nucleocytoplasmic transport. Next, we focus on XPO1 to describe some of the experimental approaches that are frequently applied to investigate its function. Finally, we illustrate the use of these approaches using the recently described case of the USP12/WDR20 complex [1] as an example.
\end{abstract}

KEYWORDS: nucleocytoplasmic transport, XPO1, NES, WDR20, USP12.

* Harremanetan jartzeko / Corresponding author: Miren Josu Omaetxebarria, Biokimika eta Biologia Molekularra Saila, Zientzia eta Teknologia Fakultatea, Euskal Herriko Unibertsitatea (UPV/EHU), Sarriena auzoa zg, 48940, Leioa, Bizkaia, Euskal Herria. - mirenjosu.omaetxebarria@ehu.eus - https://orcid.org/0000-

Nola aipatu / How to cite: Sendino, Maria; Olazabal-Herrero, Anne; Rodriguez, Jose Antonio; Omaetxebarria, Miren Josu (2020). "XP01en bidezko garraio nukleozitoplasmikoa: oinarrizko mekanismoak eta hurbilketa esperimentalak»; Ekaia, 37, 2020, 221-239. (https://doi.org/10.1387/ekaia.20861).

Jasoa: 25 maiatza, 2019; Onartua: 27 abuztua, 2019.

ISSN 0214-9001 - elSSN 2444-3255 / (c) 2020 UPV/EHU

(c) (1) Obra hau Creative Commons Atribución 4.0 Internacional-en lizentziapean dago 
Maria Sendino, Anne Olazabal-Herrero, José Antonio Rodriguez, Miren Josu Omaetxebarria

\section{SARRERA}

\subsection{Molekulen nukleoaren eta zitoplasmaren arteko garraioa}

Zelula eukariotoen nukleoan zeharreko molekula-garraioa nukleoaren mintzean mihiztatuta dauden kanal batzuetan zehar gertatzen da: nukleoko poro-konplexu deritze kanal horiei (nuclear pore complexes, NPC). Tamaina txikiko molekulek, horien artean $<30 \mathrm{kDa}$-eko proteinek ere, NPCetan zehar difusioz zeharkatu ohi dute mintza; alabaina, proteina gehientsuenak (baita oso handiak diren proteina-konplexuak ere) garraio-hartzaileei lotzen zaizkie garraia ditzaten [2, 3]. Energiaren mendeko prozesu aktiboa da proteina gehienak nukleoaren mintzean zehar garraiatzea, eta lan horretan garraiomakineria espezializatuak dihardu. Makineria horrek hiru pieza nagusi ditu: (1) NPCak, (2) garraio-hartzaile disolbagarriak, zeintzuek garraiatuko dituzten kargo-proteinen seinale espezifikoak ezagutuko baitituzte, eta (3) mintz nuklearraren alde bien arteko Ran GTPasa txikiaren gradientea, zeinak garraioaren noranzkoa zehaztuko duen [4-6] (1. irudia).

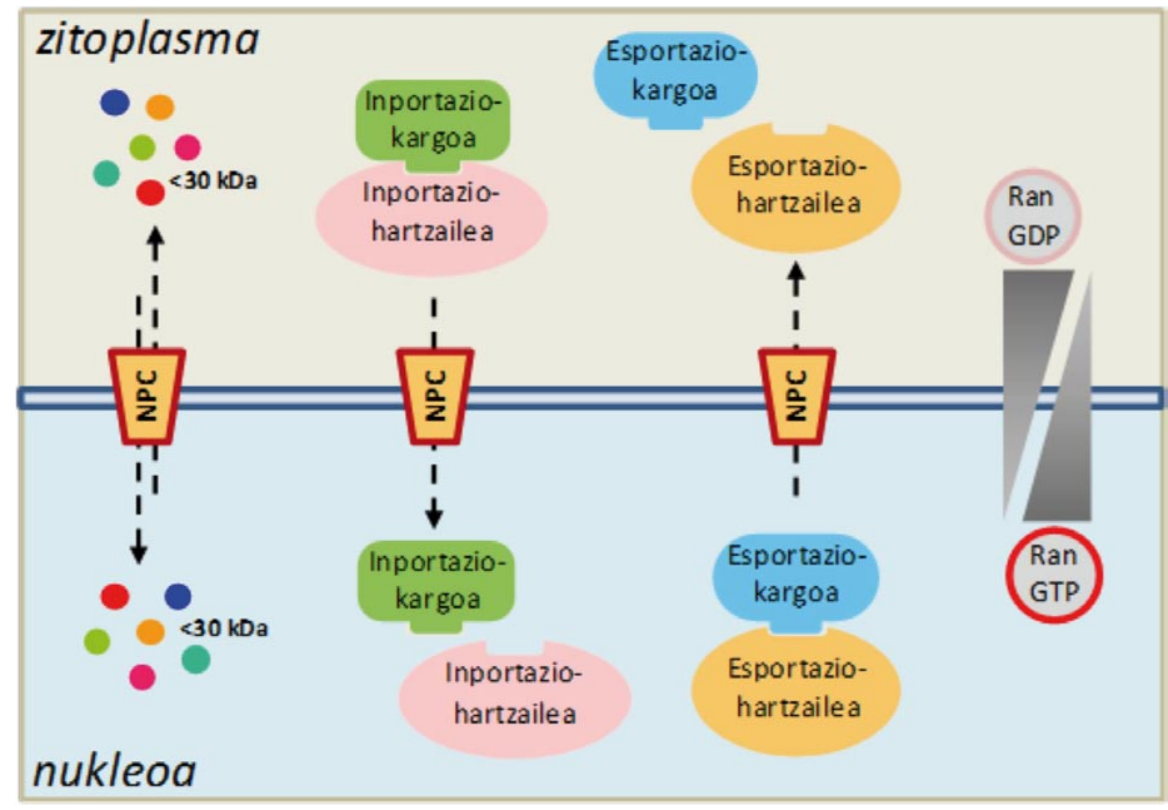

1. irudia. Nukleoko poro-konplexuetan (NPC) zeharreko proteina-garraio nukleozitoplasmikoa. Proteina txikiak $(<30 \mathrm{kDa})$ nukleoaren eta zitoplasmaren artean difusioz mugi daitezke NPCetan zehar. Proteina handiagoek, berriz, garraio- (inportazio- edo esportazio-) hartzaileen beharra dute konpartimentu batetik bestera mugitu ahal izateko. RanGTP/RanGDP gradienteak (RanGTP-kontzentrazio handia nukleoan, eta RanGDP-kontzentrazio handia zitoplasman) garraioaren noranzkoa finkatzen du. 
NPCak 30 proteina biltzen dituen nukleoporina familiako zenbait kidez osaturiko konplexuak dira. Konplexu horien ezaugarri fisiko-kimikoei esker, tamaina jakin batetik gorako proteinak ezin dira era askean mugitu nukleotik zitoplasmara edo zitoplasmatik nukleora [2, 4]. Proteina handi horiek garraio-hartzaileei lotuko zaizkie, eta nukleoporinekiko interakzio bidez, NPCa zeharkatuko dute [7].

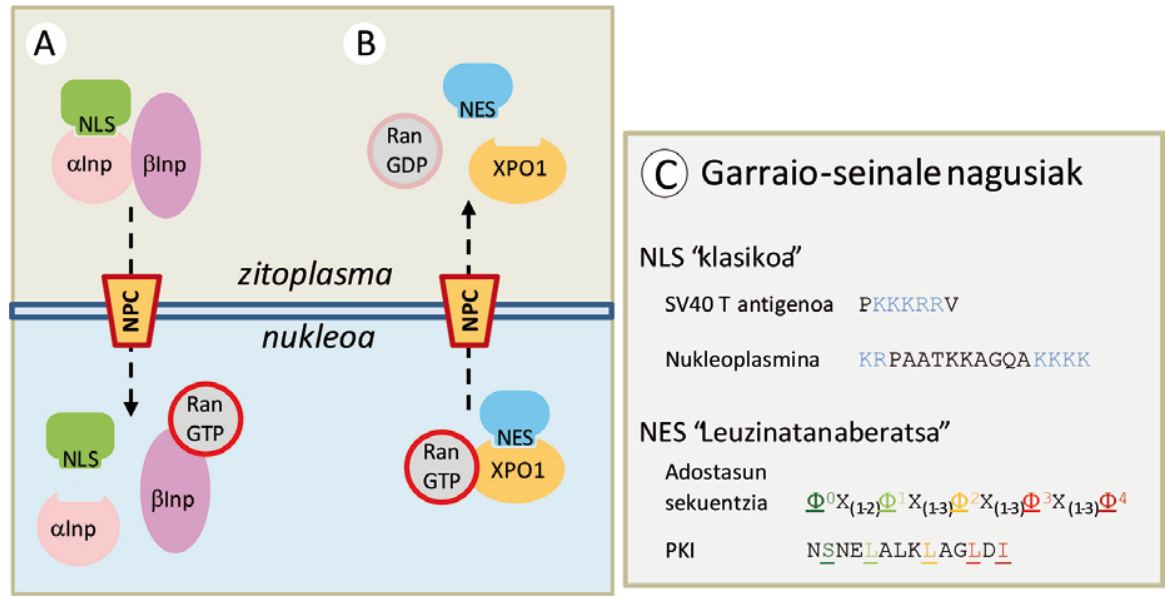

2. irudia. Garraio nukleozitoplasmikoaren mekanismo eta seinale nagusiak. A) Inportinen bidezko inportazioa: $\alpha$-inportina/ $\beta$-inportina ( $\alpha$ Inp/ $\beta$ Inp) heterodimeroak NLS motako seinalea duten kargo-proteinak zitoplasman ezagutu eta nukleoko poroetan zehar nukleora garraiatzen ditu. Inportina/NLS-kargo konplexuak, behin nukleoan dagoenean, RanGTP-arekiko interakzioan jarduten du, eta eta inportaziokoplexua desmuntatzen da. B) XPO1en bidezko esportazio-kargoen garraioa: XPO1 hartzaileak NESa duten esportazio-kargoak ezagutzen ditu eta RanGTP-arekiko elkarrekintzaz esportatuko den konplexua eratzen da. Konplexu hori, zitoplasmara heltzean, GTParen hidrolisia dela medio desmuntatu, eta XPO1 hartzailea zein esportazio-kargoa askatuko dira. C) Garraio nukleozitoplasmikorako seinale nagusiak: NLS (Nuclear Localization Signal) seinale klasikoak bi motatakoak izan daitezke; aminoazido basikozko (urdinez markaturik) errenkada bakarraz osatuak, SV40 T antigeno luzea kasu, edo aminoazido basikozko (urdinez markaturik) errenkada biz osatuak, nukleoplasminarena kasu. Bestetik, XPO1 hartzaileak ezagutu eta lotzen dituen NES (Nuclear Export Signals) seinaleak adostasun-sekuentzia batekin bat datoz, zeinean aminoazido hidrofobikoek ( $\phi$ bezala adierazita) posizio jakina betetzen duten errenkadan. Adibide moduan, PKI proteinaren NES seinalea erakusten da.

20 garraio-hartzaile inguru kodetzen ditu giza genomak [8]; horietako zenbaitzuek kargoak mintz nuklearrean zehar noranzko bietan garraia baditzakete ere, gehientsuenak nukleoranzko hartzaile gisa (inportinak) ala nukleotiko hartzaile gisa (esportinak) aritzen dira esklusiboki (2A eta 2B irudiak). Hartzaileok garraiorako seinaleak diren kargo-proteinen pepti- 
Maria Sendino, Anne Olazabal-Herrero, José Antonio Rodriguez, Miren Josu Omaetxebarria

do-sekuentzia espezifikoak ezagutu eta lotzen dituzte. Seinale horiek bitarikoak izan daitezke: nukleora lokalizatzeko seinaleak, inportinek ezagutzen dituztenak, NLSak (nuclear localization signal), eta nukleotik esportatzeko seinaleak, esportinek ezagutzen dituztenak, NESak (nuclear export sig$n a l)$. Inportaziorako ondoen karakterizatutako hartzailea $\alpha$-inportina/ $\beta$-inportina heterodimeroa da, zeinak NLS «klasikoa» (aminoazido basikozko errenkada batez edo biz osatutako peptido-sekuentzia) duten kargoak nukleorantz garraiatzea bideratzen baitu [9]. Esportinen artean, aldiz, XPO1 da karakterizatu zen lehena, eta baita gaur egun gehien ikertzen dena ere. XPO1ek arreta handia jaso du azken urteetan hainbat gaixotasunen garapenarekin lotura duelakoan. Argitalpen ugaritan adierazi da XPO1en jarduera desegokiak eragile gisara joka dezakeela zenbait minbiziren eta neuroendekapenezko gaixotasunen garapenean $[10,11]$. XPO1ek «leuzinatan aberatsak» diren NESdun proteinen esportazioa bideratzen du. Leuzinatan aberatsak diren NES horietan aminoazido hidrofobikoek (leuzina da maiztasun handienean agertu ohi den aminoazidoa, baina isoleuzina, balina, fenilalanina zein metionina ere ager daitezke) «adostasun-sekuentzia» bat osatzen duen kokapen espezifikoa dute [12] (2C irudia). Aminoazidoen adostasunsekuentzia horretaz gain, NESek konformazio jakina ere izan ohi dute: $\mathrm{N}$ muturrean, $\alpha$ helizearen egitura hartu ohi dute, eta $\mathrm{C}$ muturrean, berriz, begizta-erakoa [13]. Aipatzekoa da zenbait proteinek bi seinale motak (bai NLSa, bai NESa) dituztela eta, beraz, nukleotik zitoplasmara eta zitoplasmatik nukleora garraiatzen direla [14]. $\alpha / \beta$-inportinak eta XPO1ek ehunka proteina desberdin garraiatuko dituzte; zitoplasmatik nukleora, lehenengoak, eta nukleotik zitoplasmara, bigarrenek.

Aipatutako garraio-makineria espezializatu horren azken pieza RanGTPasa txikia da. RanGTPasa GDPri (RanGDP) edo GTPri (RanGTP) lot dakioke garraio-hartzaile eta kargoen arteko elkarrekintza erregulatzeko $[4,5,15]$. RanGDP-aren kontzentrazioa zitoplasman da altua, eta RanGTP-aren kontzentrazioa, berriz, nukleoan da altua (1. irudia). Egoera fisiologikoetan, RanGDP/RanGTP gradiente hori mantentzen da nukleoaren eta zitoplasmaren artean. Gradiente hori Ran-en bi kofaktorek mantenaraziko dute: RanGAP1 (GTPasa aktibatzailea den proteina zitoplasmikoa) eta RCC1 (kromatinari lotutako nukleotidoak trukatzeko faktorea). Nukleoko RanGTPak, inportazio- zein esportazio- konplexuekin elkarreragiten du; batetik inportina/kargo konplexuen desmuntaketa bultzatzen du, horrela inportazio-kargoa nukleoan askatuz, eta bestetik XPO1 esportazio-hartzailearekin eta haren kargoekin bat eginez RanGTP/XPO1/kargo konplexu trimerikoa osatzen du, XPO1 eta haren kargoen arteko interakzioa egonkortzeko. Konplexu hori, zitoplasmara heldutakoan, RanGAP1ek GTPa hidrolizatzearekin batera desmuntatzen da, eta esportazio-kargoa zitoplasman askatzen. Beraz, RanGTP/RanGDP gradienteak, hartzaile/kargo interakzioei eraginez, nukleoaren mintzean zeharreko garraioaren noranzkoa zehaztuko du (2A eta 2B irudiak). 


\subsection{XPO1en kargoen peskizan: hurbilketa esperimentalak}

XPO1 esportazio-hartzailearen balizko kargoak zer proteina izan daitezkeen mugatzeko eta kargoak diren horien NESak zehazteko, askotariko prozedurez baliatu gara (3. irudia).

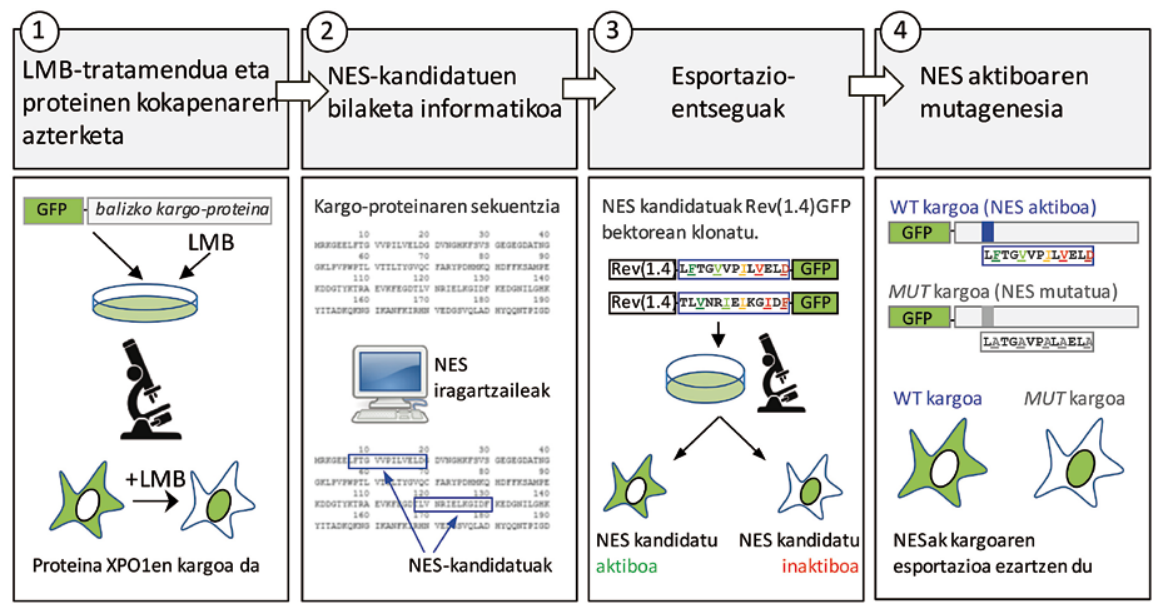

3. irudia. NES seinaleen karakterizaziorako pausoen hurrenkera. 1. Ikergai den proteina (balizko kargoa) gainadierazi eta zelulak leptomizina B-z (LMB) tratatzen dira XPO1ek proteina hori esportatzen duenetz aztertzeko. Behin XPO1ek esportatzen duela ebatzita, proteina horren delezio-mutanteak sortu, eta horiek zelulan hartzen duten kokapena azter daiteke, eta, honela, NES seinalea egon daitekeen zonaldea mugatu. 2. Paraleloan, proteinaren sekuentzia Wregex edo LocNES bezalako NES-iragarleak erabiliz mapatzen da. Iragarle horiek erakusten dute NES seinalea non koka daitekeen proteinaren sekuentzian zehar. 3. Lehen bi pausoen ostean, NES-kandidatuak hautatzen dira, eta horiek Rev(1.4)-GFP bektorean klonatzen dira esportazio-entseguak egiteko [27]. 4. Behin esportazio-entseguan NES aktiboa dela ebatzita, NESa mutatu egiten da proteina osoaren testuinguruan. Identifikatutako NESak kargoaren esportazioa ezartzen badu, NESaren mutazioak kargoaren kokapena aldatzea espero dugu. Horrela, NESaren funtzionaltasun biologikoa berrets daiteke. [WT kargoa: wild type kargoa (mutatugabeko NESdun kargoa); MUT kargoa: mutatutako NESdun kargoa].

\subsubsection{Leptomizina B-k(LMB) eragindako XPOlen bidezko esportazioaren inhibizioa}

CRM1 (chromosome region maintenance factor 1) proteinak beste proteina batzuk nukleotik esportatzeko hartzaile-lanetan ere jarduten zuela ikusi zuten 1997an, eta, orduz geroztik, exportin 1 (XPO1) izena ere hartu du [16-19]. Garai hartan argitaratutako lanek XPO1 nukleotiko esporta- 
Maria Sendino, Anne Olazabal-Herrero, José Antonio Rodriguez, Miren Josu Omaetxebarria

zioa inhibitzen duen LMBren itua dela frogatu zuten. Streptomyces bakterioak ekoizten duen metabolitoa da LMB; izan ere, aurkitu zutenean, antifungiko eraginkorra zela ikusi zuten [20]. Urte batzuk geroago, baina, ikusi zen LMBk XPO1ek bideratutako nukleotiko-esportazioa oztopatzen zuela [21]. 2009an ezagutarazi zen kargoen NESek XPO1i lotzerakoan okupatzen zuten eskualdearen egitura; hori horrela, NESak XPO1en poltsiko hidrofobiko jakin batera lotzen zirela ondorioztatu zen [13]. Aurkikuntza horrekin batera, ezagutu zen, halaber, LMB ere poltsiko hidrofobiko berberera lotzen dela, eta, honela, LMBk, poltsikoa okupatuz gero, kargoen NESak lotzea eragozten du. Aurkikuntza horrek XPO1en kargoak identifikatzeko lanak asko erraztu ditu; izan ere, LMB erabilitakoan XPO1en zitoplasmako kargoak maiz nukleora birlokalizatzen direla ikusi da zeluletan egindako esperimentuetan. Prozedura horrek badu bestelako abantaila bat; izan ere, LMB, kargo endogenoen portaera aztertzeko baliagarria izateaz gain, ektopikoki gainadierazitako kargoen esportazioa ikertzeko ere aproposa da. Honela, kargo-errepertorio zabala aztertzeko aukera emateaz gain, kargoen sekuentzietan delezio ituratuak eginez, horien NESak mapatzeko ere balia dezakegu LMB tratamendua. Hurbilketa hori, baina, ezin da konstitutiboki nukleora lokalizatzen diren proteinen XPO1 bidezko esportazioa frogatzeko erabili. Kasu horietan, hartzailea ektopikoki gainadieraz daiteke NESdun nukleoko kargoak zitoplasmara esportatzea eraginez [22].

Alabaina, kargo-kandidatuak XPO1en benetako kargoak direla frogatzeko eta, era berean, kargoak diren horien NESak identifikatu eta zehazteko, LMBren erabileran oinarritutako esperimentuez gain, bestelako hurbilketa batzuk beharrezkoak dira. Azken urteetan ikerketa esperimentalarekin batera ezinbesteko bihurtu den bioinformatikaren ekarpena ere aipatzekoa da lan honetan.

\subsubsection{Analisi bioinformatikoa: NES-iragarleak}

Adierazi bezala, leuzinatan aberatsak diren esportazio-seinaleak, NESak, aminoazido-motibo laburrak dira, zeinek kargo-proteinak XPO1 esportazio-hartzaileari lotzea ahalbidetzen duten. NES seinaleak, baina, askotarikoak dira, eta, horiek aurresateko, erreminta informatiko eraginkorrak eskura izatea garrantzitsua da oso. Badira gaur egun eskuragai zenbait NES-iragarle: esaterako, ELM [23], NetNES [24], NESsential [25] edota gure taldeak garatutako Wregex izenekoa [26]. Azken honek kargo-kandidatuen fidagarritasunaren hurrenkera zehazten du, eta modu horretan, lehentasunak markatzen dira esperimentalki ikergai izango diren kargoen artean. Benetako kargoak izateko aukera handienak dituzten aurresandako kandidatuak esperimentalki aztertuko ditugu. 
(A) $\operatorname{Rev}(1.4)-G F P$ bektorea
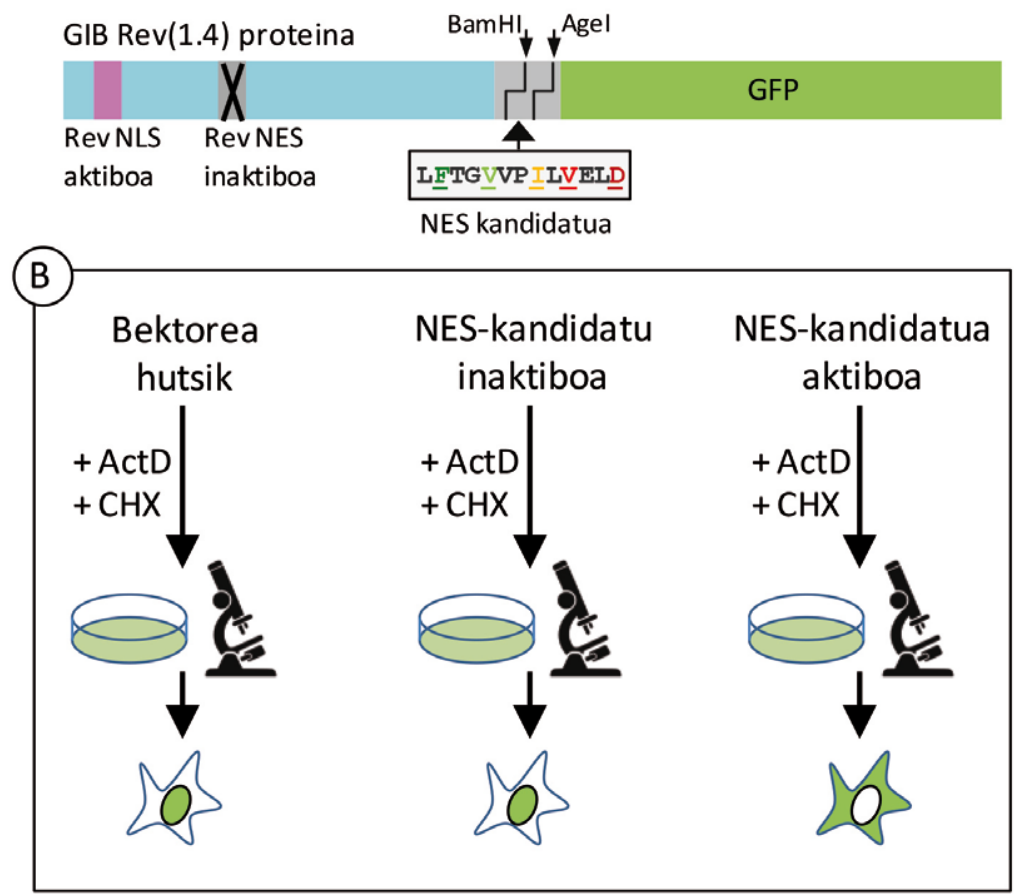

4. irudia. Esportazio-entseguaren nondik norakoak. A) $\operatorname{Rev}(1.4)$ GFP plasmidoak kodetzen duen fusio-proteinaren irudi eskematikoa. Urdinez, Rev(1.4) proteina, non NES inaktiboa (grisez, gurutzea) eta NLS aktiboa (arrosaz) ageri diren. Berdez, GFP proteina. Plasmidoan, Rev(1.4) eta GFP kodetzen dituzten sekuentzien artean, BamHI eta AgeI murrizketa-lekuak daude, zeinak NES-kandidatua klonatzeko erabiliko diren. B) Esportazio-entseguan esperotako emaitzak: bektorea hutsik baldin badago kokapen nuklearra agertzen du; gauza bera gertatzen da klonatutako NES-kandidatua inaktiboa baldin bada. Aldiz, NES-kandidatua aktiboa bada, seinalea zitoplasman agertzen da [27]. ActD eta CHX erabilpenaren zehaztasunak Material eta Metodoak atalean daude deskribatuta.

\subsubsection{NES-kandidatuen gaineko esportazio-entseguak}

Henderson eta Eleftheriouk 2000. urtean garatu eta argitaratutako esportazio-entsegua da gure lan-fluxuan erabilitako prozedura baliagarrienetako bat [27]. Entsegu horretako pieza gakoa Rev(1.4)-GFP fusio-proteina da (4A irudia). Fusio-proteina horrek hiru zati ditu: (1) NESa mutatuta duen, hau da, esportatzen ez den GIB birusaren Rev proteina, $\operatorname{Rev}(1.4)$ 
Maria Sendino, Anne Olazabal-Herrero, José Antonio Rodriguez, Miren Josu Omaetxebarria

deritzona, (2) BamHI/AgeI murrizketa-lekuak, non ikergai diren NESak klona daitezkeen, eta (3) GFPa (green fluorescent protein). Rev(1.4)-GFP proteina, berez, hau da, hutsik, nukleoan kokatzen da; izan ere, Rev proteinak berezko NLS funtzional bat ere badu, zeinak proteina osoa nukleora inportatzea eragiten duen. Baina BamHI/AgeI arteko leku horretan NESkandidatu aktibo bat sartuko bagenu, sortutako fusio-proteina berri hori zitoplasmara esportatuko litzateke, baldin eta Rev(1.4)-GFPk berezkoa duen NLSaren «indarra» gaindituko balu. Entseguaren emaitzaren arabera, beraz, NES-kandidatuak baieztatu edo baztertzen ditugu, eta NES aktiboen «indarra» ezagutzen dugu (4B irudia).

\subsubsection{NES aktiboen mutagenesi ituratua: funtzionaltasun biologikoaren berrespena}

Esportazio-entseguaren emaitzaren arabera aktibotzat ebatzi dugun NESa mutatu egingo dugu, honek XPO1en bidezko kargoaren garraioan izan dezakeen funtzionaltasuna berraztertu eta behar den kasuetan berresteko. Jatorrizko NES basatidun (wild type, WT) kargoa esportatu egingo litzateke, eta mutatutako NESdun kargoak, berriz, eragindako mutazioak direla eta, ezingo luke XPO1ekin elkarreragin eta, beraz, ezin izango litzateke nukleotik zitoplasmara esportatu. Modu honetan, lan-fluxu osoan zehar aktibotzat jo dugun NES-kandidatu jakin baten funtzionaltasuna berretsiko dugu, hala dagokionean.

LMBren erabilera aitzindaritik hasi eta osteko esportazio-entsegu eta eskala handiko proteomikako lanetaraino, hurbilketa guztien uztarketa ezinbestekoa da XPO1en kargoen errepertorioa (XPO1en «esportoma») osatuz joateko. Azken 15 urteetan, XPO1ek esportatutako 200 kargo inguru identifikatu dira modu fidagarrian [12] eta, berriki, masa espektrometriaren erabilerak XPO1en balizko kargoen bilduma 1.000 proteina baino gehiagotara zabaldu du [28].

\subsection{XPO1en kargoen peskizan: USP12/WDR20 konplexuaren kasua adibide}

Atarian adierazi legez, XPO1ek milaka proteinaren garraio nukleozitoplasmikoa bideratzen du eta, beraz, zelulan gertatzen diren prozesu ugariren erregulazioan gako da. Prozesu ugari horien artean, ubikuitinazio-bidezidorrak ditugu. Ubikuitinazioa itzulgarria den itzulpen osteko eraldaketa da, eta zeluletako proteina gehientsuenen egonkortasuna, funtzioa edota kokapena zuzentzen ditu. Deubikuitinasak (DUBak) ubikuitina-unitateak proteinetatik kentzen dituzten entzimak dira, eta funtsezko eginkizuna dute prozesu fisiologiko ugaritan [29]. Gure taldeak garraio nukleozitoplasmikoaren eta ubikuitinazioaren arteko lotura [30] ikertzen du. Esate baterako, 2012. urtean, DUB familiako zenbait kide- 
ren NESak zehazteari ekin genion, eta horien funtzionaltasuna aztertu genuen [31].

100 giza DUB inguru daude 7 familiatan sailkatuta; familiarik handiena USP (ubiquitin-specific proteases) izenekoa da. Entzima-familia horretako kide batek, USP12 izenekoak, tumore ezabatzaile gisa jarduten duela ikusi da $[32,33]$. Baina USP12k, berez, ez du aktibitate deubikuitinatzailerik, ez bada WDR20 eta UAF1 kofaktoreekin lotzen. Bi proteina horiek sinergistikoki jarduten dute, eta USP12ren aktibitate entzimatikoa handiagotzen. USP12k zelulen fisiologian duen garrantzia ezaguna bada ere, oraindik ez dago argi non, zein konpartimentutan kokatzen den zelulan, ezta aipaturiko bi kofaktoreek zer-nolako eragina izan dezaketen lokalizazio horretan, eraginik izatekotan. Kontu horrek eztabaidagai dirau gaur egun ere: ikerketa-lan batzuek USP12 gehienbat zitoplasmikoa dela diote [34-38], eta beste batzuek, aldiz, batez ere nuklearra dela [39, 40]. Argi dagoena da USP12 atzera eta aurrera mugitzen dela nukleoaren eta zitoplasmaren artean, eta mugimendu hori XPO1ek bideratzen duela [41, 40]. USP12aren NES bat deskribatu dute oraintsu Sanyal eta lankideek [40, 42]. Aurreko atalean azaldutako lan-fluxua erabilita, gure taldeak lortutako emaitzek iradokitzen dute deskribatutako NES hori ez dela modu argi eta nabarmenean esportaziorako seinale gisa aritzen. Bestalde, Kirli eta lankideek 2015. urtean zerrendatutako XPO1en HeLa zelulen mila kargo baino gehiagoren artean, WDR20 ageri da, USP12ren kofaktorea dena [28]. Hori guztia kontuan hartuta, guk honako hipotesia planteatzen dugu: USP12/WDR20 konplexuaren XPO1en bidezko esportazioa USP12k ez baizik WDR20k gidatu dezakeela. Gainera, hipotesi horrekin bat eginez, XPO1en menpekoa den USP12/WDR20 konplexuaren esportazioa bideratzen duen WDR20ren NES funtzional berri bat identifikatu dugu.

\section{MATERIAL ETA METODOAK}

\subsection{Prozedura orokorrak: zelulen hazkuntza, transfekzioa eta mikroskopioan behatzeko laginen prestaketa}

HeLa zelulak \% 10 idi-umeki serodun (ingelesez fetal bovine serum, $F B S$ ) eta \% 1 penizilina/estreptomizinadun DMEM (Dulbecco's modified Eagle's medium) medioan hazi ditugu (dena Invitrogen-ekoa) $37^{\circ} \mathrm{C}$-an, $\%$ 5eko $\mathrm{CO}_{2}$-dun atmosferan. 24 ordu transfekzioa egin aurretik, zelulak 12 putzuko plaketan erein ditugu. Transfekzioak X-tremeGENE 9 transfekzio-agentea (Roche Diagnostics) erabiliz egin ditugu, fabrikatzailearen argibideei jarraituz.

Dagokien tratamendua jaso ostean, zelulak \% 3,7 formaldehido PBStan fixatu ditugu 30 minutuz, eta DAPI-dun Vectashield muntaketa-medioa erabilita (Vector Laboratories), portetan muntatu ditugu. 
Maria Sendino, Anne Olazabal-Herrero, José Antonio Rodriguez, Miren Josu Omaetxebarria

\section{1. pausoa. Plasmidoen prestaketa, LMB tratamendua eta proteinen kokapenaren azterketa}

Gure intereseko proteinak diren USP12 eta WDR20 proteinen aurkako komertzialki eskuragarri dauden antigorputzak inespezifikoak izan ohi dira. Horrek arazo larria dakar, intereseko proteinez gain bestelako ituak ezagutu ditzaketelako antigorputzok. Hori horrela izanik, intereseko proteinak gainadierazteko helburuz, proteinok sustatzaile beraren pean klonatu ditugu YFP (yellow fluorescent protein) izeneko proteina fluoreszentearekin batera, pEYFP-C1 (Clontech) izeneko plasmidoan. Klonatutako intereseko proteina YFPrekin batera adierazten denez fusio-proteina gisara, adierazitako fluoreszentziaren behaketak intereseko proteinaren jarraipena egitea ahalbidetzen digu; hau da, zelulan non kokatzen den ikustea ahalbidetuko digu. Kasu honetan, USP12 eta WDR20 proteina basatien cDNA sekuentzien gBlock-ak (IDT) pEYFP-C1 plasmidoaren BamHI eta HindIII murrizketa-lekuen artean klonatu ditugu; ostean, HeLa zeluletan gainadierazi eta, fluoreszentzia-mikroskopioan aztertu dugu bi proteina horien kokapena. Prozedura berberari jarraitu diogu PCR bidez ekoitzitako WDR20ren delezio-mutanteak pEYFP-C1 plasmidoan klonatu eta gainadierazteko.

USP12, WDR20 eta azken honen delezio-mutanteen kokapena aztertzeko, transfekzioa egin eta 24 ordura HeLa zelulak $6 \mathrm{ng} / \mathrm{ml}$ LMB (Apollo Scientific) esportazio-inhibitzailez tratatu ditugu hiru orduz.

\section{2. pausoa. NES sekuentziaren iragarleen bidezko bilaketa}

WDR20 proteinaren NES seinalea aurresateko, Wregex (http://ehubio. ehu .eus/wregex) [26] erreminta bioinformatikoa erabili dugu.

\section{3. pausoa. Esportazio-entseguak eta entseguetan erabilitako plasmidoak}

pRev(1.4)-GFP bektorea (4A irudia) Beric Hendersonen (Westmead Institute for Cancer Research, University of Sydney, Australia) eskutik lortu dugu. USP12ren zein WDR20ren NESen cDNA-sekuentziak pRev(1.4)-GFP plasmidoaren BamHI eta AgeI murrizketa-lekuen artean klonatu ditugu. Klonatutako USP12 eta WDR20ren NES sekuentziak honakoak dira: ${ }^{75}$ RKKESLLTCLADLFHSIAT ${ }^{93}, \operatorname{Rev}(1.4)$-NESUSP12_GFPren kasuan eta ${ }^{450}$ MDGAIASGVSKFATLSLHD ${ }^{468}, \operatorname{Rev}(1.4)$-NES WDR20 GFPren kasuan. Bai bi plasmido horiek eta bai kontrol negatibotzat hartuko dugun Rev(1.4)-GFP hutsa, HeLa zeluletan transfektatu ditugu. Hiru plasmidoetako bakoitza plakako bi putzu transfektatzeko erabili dugu. Zelulen transfekzioa egin eta 24 ordura, bi putzuetako bat $10 \mu \mathrm{g} / \mathrm{ml}$ zikloheximidaz (CHX; Sigma) tratatu dugu 3 orduz; besteari, berriz, $10 \mu \mathrm{g} / \mathrm{ml} \mathrm{CHX}$ gehi $5 \mu \mathrm{g} / \mathrm{ml}$ aktimomizina D (ActD, Sigma) gehitu dizkiogu. Zikloheximida proteinen sintesia geldiarazten duen farmakoa da eta, beraz, horrekin tratatutako zeluletan, zitoplasman behatzen den seinale fluoreszentea 
nukleotik zitoplasmara esportatu den GFP fusio-proteinaren seinalea da, eta ez zitoplasman sintetizatu berri den proteinarena. Bestetik, ActD farmakoak Rev(1.4) proteinaren NLSak gidatutako nukleoranzko inportazioa oztopatzen du eta, beraz, klonatutako NES ahulagoen aktibitatea ere sumatzea ahalbidetuko digu. Ikergai diren NESen aktibitatea zehazteko, bai kontrol negatiboarekin (Rev(1.4)-GFP hutsa) bai gure intereseko konstruk-

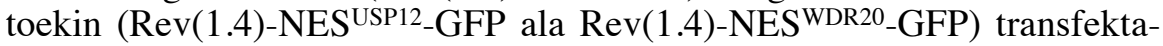
tutako laginetako gutxienez 200 zelula zenbatu ditugu; 200 zelulen artean seinale zitoplasmikoa, seinale nuklearra ala seinale nukleozitoplasmikoa zein proportziotan behatu dugun kalkulatu dugu. Proportzio horien arabera, 0 eta 9ra arteko eskalan sailkatuko dugu aztertzen ari garen NESen aktibitatea edo indarra [27].

\section{4. pausoa. NESen mutagenesi ituratua}

Azkenik, NESek proteina osoaren testuinguruan duten eragina aztertzeko, proteina basatien (USP12 WT eta WDR20 WT) eta mutatutako NESak dituzten proteinen (USP12 NESmut eta WDR20 NESmut) portaera alderatu dugu. Mutatutako NESak dituzten proteinak ekoizteko, jatorrizko proteinak moldetzat hartu, eta mutagenesi ituratua egin dugu QuikChange Lighting Site-Directed Mutagenesis Kit-a (Stratagene) erabiliz. 1. pausoan USP12 eta WDR20 proteina basatietarako azaldutako prozedura berbera erabilita, YFP-USP12 NESmut eta YFP-WDR20 NESmut proteinek HeLa zeluletan duten kokapena aztertu dugu. Emaitzok proteina basatiekin lortutako emaitzekin alderatu ditugu.

\section{EMAITZAK}

\subsection{USP12k eta WDR20k XPO1 hartzailearen mendeko garraioa jasaten dute}

Lehenik eta behin, gainadierazitako USP12 deubikuitinasak eta haren kofaktorea den WDR20 proteinak zeluletan duten berezko kokapena aztertu dugu, eta bi proteinek kokapen zitoplasmikoa dutela ikusi dugu LMBrik gabeko (-LMB) laginetan. Alabaina, YFP-WDR20ren seinalea zitoplasmikoa da nabarmen, eta nukleoetan berriz, ezin beha daiteke seinalerik (6B irudia); YFP-USP12ren kasuan, aldiz, ahula bada ere, nukleoetan beha daiteke nolabaiteko seinalea (5A irudia). LMBren tratamenduaren mendeko (+LMB) XPO1en inhibizioak bi proteinen kokapenean eraginik duenetz ere aztertu dugu, eta bai YFP-WDR20ren kokapena bai YFP-USP12ren kokapena zitoplasmikoa izatetik nukleozitoplasmikoa izatera pasatu dela ikusi dugu; kasu bietan, nukleoetan behatzen den seinalea nabarmenagoa da -LMB laginetakoa baino (5A eta 6B irudiak). Hortaz, USP12 eta WDR20 proteinek XPO1 hartzailearen mendeko garraioa jasaten dute. 


\subsection{Aurretiaz proposaturiko USP12ren NESa inaktiboa da}

USP12 proteinaren ${ }^{77}$ KESLLTCLADLFHSI ${ }^{91}$ aminoazido-errenkada XPO1en mendeko garraiorako NES gisa proposatu da oraintsu [40, 42]. Proposatutako NES hori ez dator guztiz bat leuzinatan aberatsak diren NESen adostasun-sekuentziarekin (2C irudia); horretaz gain, ustezko NESa berresteko esportazio-entsegurik ez dute burutu egileek. Gauzak horrela, Rev(1.4)-NESUSP12_GFP fusio-proteinak zelulan duen kokapena aztertu dugu esportazio-entseguetan [27].

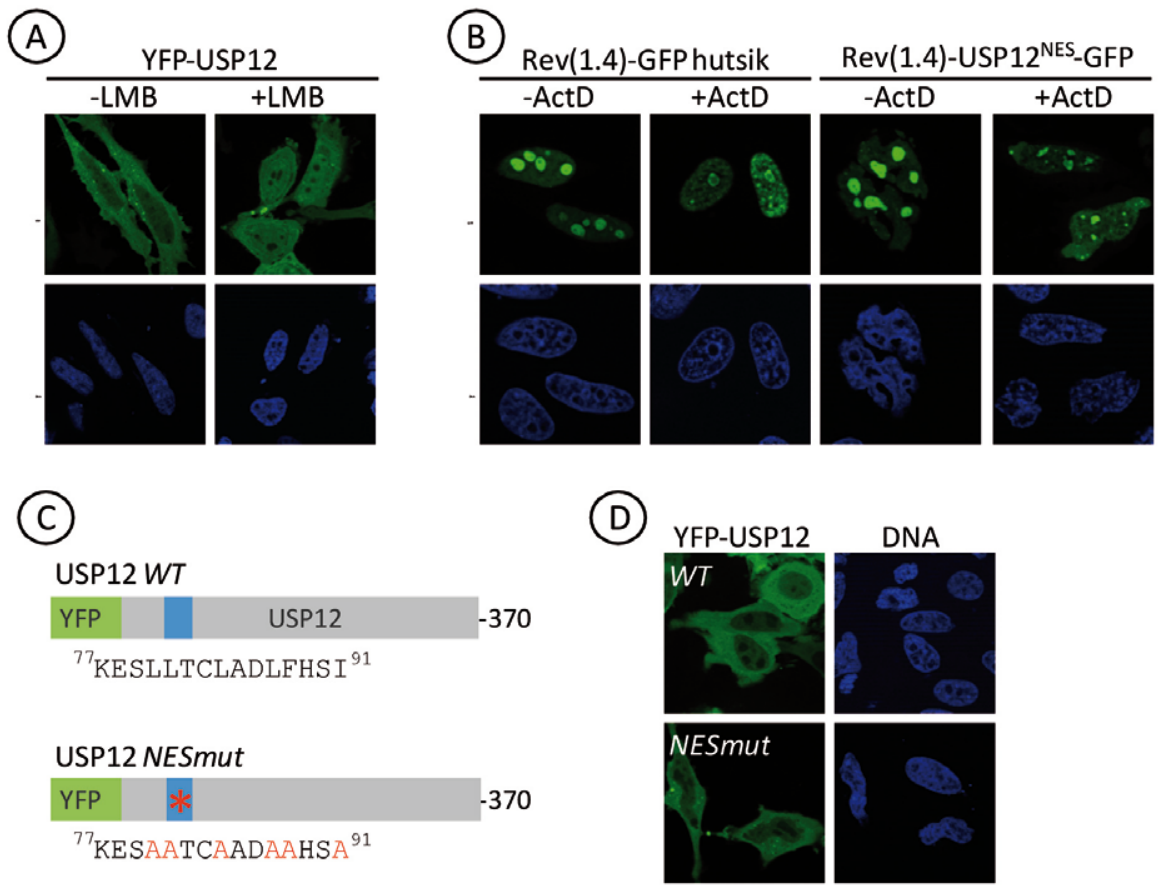

5. irudia. USP12 proteinaren ustezko NES sekuentziaren analisia. A) YFPUSP12 proteina, HeLa zeluletan gainadierazia, LMBz tratatua (+LMB) eta tratatu gabea (-LMB). Tratatu gabeko laginean, batez ere kokapen zitoplasmikoa du YFPUSP12 proteinak; tratatuta, aldiz, kokapen nuklearra eta zitoplasmikoa hartzen du. B) HeLa zeluletan eginiko esportazio-entseguaren irudiak: antzeko kokapena agertzen dute Rev(1.4)-GFP kontrol negatiboak eta USP12 proteinan deskribatutako NESa kodetzen duen plasmidoak (Rev(1.4)-NESUSP12_GFP). Hau da, ustezko NES sekuentzia hori ez da NES funtzional bat. Saiook ActD gehituz (+ActD) ala gehitu gabe (-ActD) egin ziren. C) USP12 fusio-proteina basatiaren (WT) eta NES mutatua duen (NESmut) fusio-proteinaren adierazpen eskematikoa. Mutatutako NESaren sekuentzian, aldatutako aminoazidoak gorriz erakusten dira. D) YFP-USP12 WT eta YFP-USP12 NESmut gainadierazten dituzten HeLa zelulen irudi konfokalak: proteina basatiak zein mutanteak kokapen zitoplasmikoa agertzen dute. Prestakinetako zelula-nukleoak DAPI tindaketaren bidez behatu dira. (1. erreferentziatik hartutako eta moldatutako irudia, Elsevierren baimenarekin). 


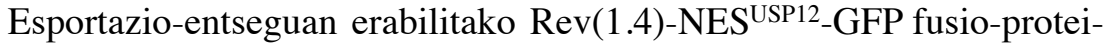
nak ez du Rev(1.4)-GFP kontrol negatiboak baino kokapen zitoplasmikoagoa agertzen, ezta ActD-ren presentzian ere (5B irudia). Beraz, esportazioentsegu horren emaitzek iradokitzen dute 2016an proposaturiko ustezko NES sekuentzia hori ez dela NES funtzional bat.

Proposaturiko NESak aktibitaterik erakutsi ez arren, proteina osoaren testuinguruan izan dezakeen funtzionaltasun biologikoa aztertzeko, mutagenesi-esperimentua egin dugu. Horretarako, YFP-USP12 basatiaren (USP12 WT) ${ }^{77}$ KESLLTCLADLFHSI ${ }^{91}$ sekuentziatik aldatu ditugu leuzinatan aberatsak diren NESetan agertzen diren ohiko aminoazidoak; hortaz, NES mutatuaren (NESmut) sekuentzia honakoa da: ${ }^{77} \mathrm{KES}$ AATCAADAAHSA ${ }^{91}$ (5C irudia). Gainadierazitako YFP-USP12 WT eta YFP-USP12 NESmut proteinek zelulan zer kokapen duten aztertutakoan, ikusi dugu proteina biek kokapen zitoplasmikoa agertzen dutela (5D irudia). Beraz, USP12ren ${ }^{77}$ KESLLTCLADLFHSI $^{91}$ sekuentziak ez du proteinaren esportazioa gidatzen.

\subsection{WDR20 proteinak haren kokapen nukleozitoplasmikoa gidatzen duen NES aktiboa du}

Behin WDR20k XPO1en mendeko esportazioa jasaten duela egiaztatuta (6B irudia), haren NES seinalea zein den ikertu dugu. Ezaguna da NES seinale aktibo ohikoenek $\alpha$ helizearen erako egitura sekundarioa hartzen dutela amino-muturrean [13]. WDR20-USP12-UAF1 konplexua X izpien difrakzioa erabiliz aztertu bada ere [43], ez da $\alpha$ helizerik zehaztu WDR20 proteinaren kasuan. Alabaina, WDR20ren 394 eta 509 aminoazidoen arteko egitura zehaztea oraindik lortu ez denez [43], pentsatu genuen alde horretan $\alpha$ helizeren bat egon zitekeela eta, ondorioz, NESa izan zitekeen sekuentzia. Hortaz, YFP-WDR20ren hiru delezio-mutante egin ditugu; 1-390, 390-510 eta 510-569 aminoazidoen arteko zatiak direnak, hain zuzen ere (6A irudia). WDR20 proteina osoarekin egin bezala, zati horien kokapen zelularra ere zelulak LMBz tratatuz eta tratatu gabe aztertu dugu. YFP-WDR20(1-390) eta YFP-WDR20(510-569) zatiek kokapen nukleozitoplasmikoa hartzen dute, bai LMBz tratatutako laginetan bai tratatu gabeko laginetan. YFP-WDR20(390-510) zatiak, aldiz, proteina osoak zitoplasmatik nukleora jotzeko duen jokaera bera mantentzen du. Hau da, LMB tratamendurik gabe guztiz zitoplasmikoa da; LMBren presentzian, aldiz, kokapen nukleozitoplasmikoa hartzen du (6B irudia). Emaitza horrek WDR20 proteinaren NES seinalea 390 eta 510 aminoazidoen artean kokatuta dagoela ematen du aditzera. 
Maria Sendino, Anne Olazabal-Herrero, José Antonio Rodriguez, Miren Josu Omaetxebarria
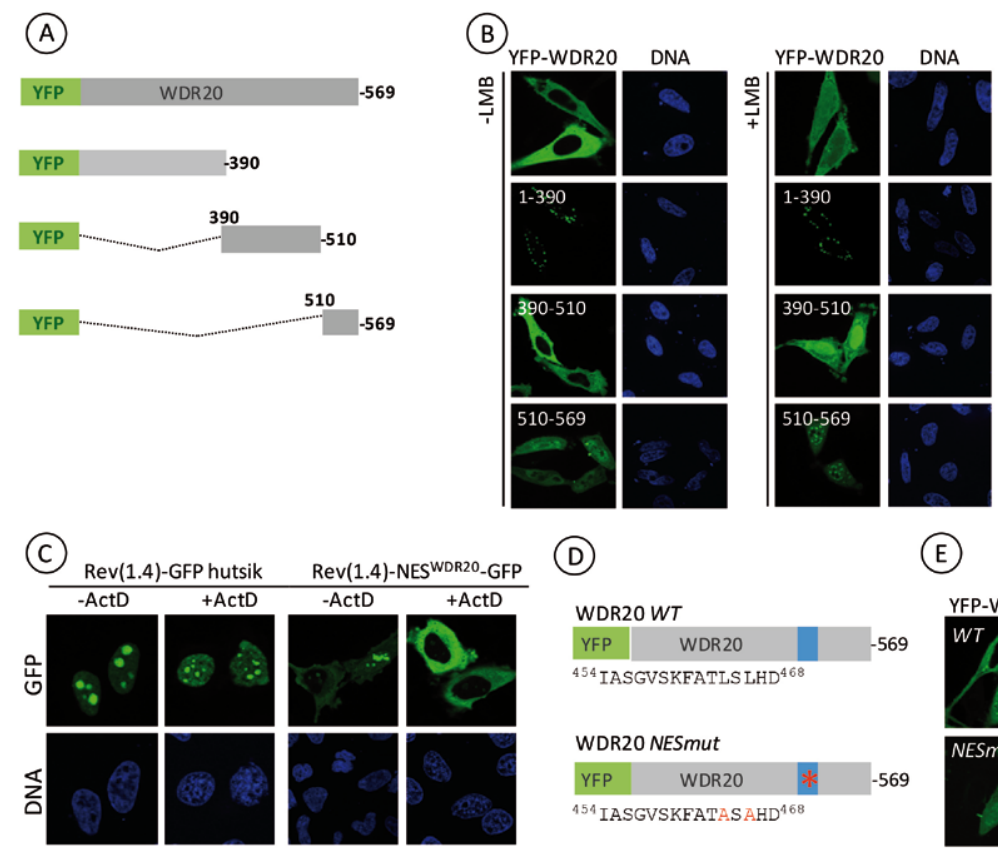

(D)

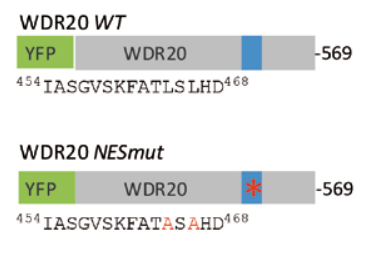

(E)

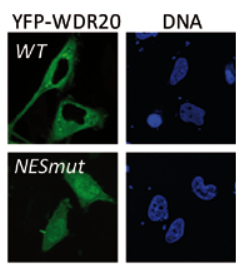

6. irudia. WDR20 proteinaren NESaren identifikazioa. A) YFP-WDR20 proteinaren delezio-mutanteen irudi eskematikoa. B) YFP-WDR20 osoa zein zatiak, HeLa zeluletan gainadierazita, LMBz tratatuta $(+\mathrm{LMB})$ zein tratatu gabe (-LMB). WDR20 proteina osoak kokapen zitoplasmikoa du tratatu gabeko laginetan; LMBz tratatzean, aldiz, kokapen nukleozitoplasmikoa hartzen du. Zatiei erreparatuta, aldiz, LMB tratamenduak ez du YFP-WDR20(1-390) ez YFPWDR20(510-569) zatien kokapena aldatzen. YFP-WDR20(390-510) zatiaren kokapena, aldiz, proteina osoarekin gertatzen den modu berean, zitoplasmikoa izatetik nukleozitoplasmikoa izatera pasatzen da LMB tratamenduaren ondorioz. C) WDR20 proteinaren cNESa aztertzeko asmoz HeLa zeluletan ActD-z tratatuta (+ActD) eta tratatu gabe (-ActD) Rev(1.4)-[NESWDR20]-GFP eta Rev(1.4)GFP bektore hutsek esportazio-entseguan erakutsitako kokapenaren irudi kon-

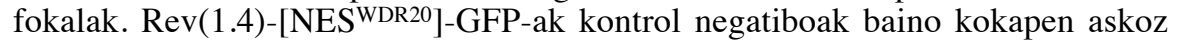
ere zitoplasmikoagoa du. Horrek adierazten du WDR20 proteinaren proposatutako NESak haren esportazioa bultzatzen duela, hau da, NESa aktiboa dela. D) WDR20 basatidun (WT) eta WDR20 NES mutantedun (NESmut) fusio-proteinen adierazpen eskematikoa. Jatorrizko 464 eta 466 leuzinak alaninaz ordezkatu dira mutantean (gorriz adierazita). E) YFP-WDR20 basatia eta YFP-WDR20 mutantea, HeLa zeluletan gainadieraziak. NES mutantedun YFP-WDR20 proteinak zelulan duen kokapena YFP-WDR20 basatiak LMBz tratatutakoan duen kokapenaren oso antzekoa da. Prestakinetako zelula-nukleoak DAPI tindaketaren bidez behatu dira (1. erreferentziatik hartutako eta moldatutako irudia, Elsevierren baimenarekin). 
WDR20 proteinaren NES seinalea zein den zehazteko, Wregex [26] erreminta bioinformatikoa erabili dugu. Wregex-ek WDR20 proteinean iragarritako balizko 9 NES-kandidatuetatik bakarra kokatzen da 390510 aminoazidoen artean. NES-kandidatu horren sekuentzia honakoa da: ${ }^{450}$ MDGAIASGVSKFATLSLHD ${ }^{468}$. Material eta Metodoak ataleko 3. pausoan azaldutako prozedura berari jarraituz esportazio-entsegua egin dugu NES horren aktibitatea aztertzeko, eta, behatutakoaren arabera, NESaren indarra 6+ koa da; hau da, NESa aktiboa da (6C irudia). WDR20ren NESa aktiboa dela ikusita, proteina osoaren testuinguruan duen funtzionaltasuna aztertu dugu. Horretarako, NESaren sekuentziako L464 eta L466 aminoazidoak mutatu dira, leuzinak alaninaz ordezkatuta (6D irudia). Mutatutako NESdun WDR20k berezko kokapen nukleozitoplasmikoa agertzen duela ikusi dugu, eta kokapen hori WDR20 basatiak LMBz tratatutakoan duen kokapen bera da (6E irudia). Hortaz, baiezta dezakegu WDR20ren ${ }^{450}$ MDGAIASGVSKFATLSLHD ${ }^{468}$ aminoazido-sekuentzia dela nukleotiko haren esportazioaren eragilea.

\section{EZTABAIDA ETA ONDORIOAK}

USP12/WDR20 konplexuaren adibideak erakusten du deskribatutako hurbilketa esperimentala XPO1en esportazio-kargoak karakterizatzeko hurbilketa egokia dela. Gure lanean lortutako emaitzek aditzera ematen dute USP12 proteinarako proposatutako NESak [40, 42] ez duela USP12ren esportazioa eragiten. Bestetik, USP12ren kofaktorea den eta masa espektrometriaren bidez XPO1en balizko kargotzat identifikatutako WDR20ren [28] NES aktiboa zehazki karakterizatu dugu. Saccharomyces pombe legamian, USP12/WDR20 konplexuaren homologoa den Ubp9/ Bun62 konplexuaren garraioa Bun62 (WDR20 homologoa) kofaktorearen mendekoa da [41]. Homologia hori aintzakotzat hartuta, eta gure emaitzak ikusita, USP12/WDR20 konplexuaren garraioaren arduraduna WDR20 dela pentsatzen dugu.

\section{ESKER ONAK}

Lan honetako mikroskopio-analisiak UPV/EHUko mikroskopia-zerbitzuan (SGIker) egin dira. Lan hau Espainiako Gobernuaren MINECOFEDER (SAF2014-57743-R), Eusko Jaurlaritzaren (IT1257-19) eta Euskal Herriko Unibertsitatearen (UPV/EHU) (UF111/20) finantziazioei esker egin da. Baita Eusko Jaurlaritzak (MS-ri) eta Euskal Herriko Unibertsitateak (UPV/EHU) (AO-Hri) emandako dirulaguntzei esker ere. Gure taldea PROTEOSTASIS BM1307 COST Action-eko kide da, European Cooperation in Science and Technology-k lagunduta. 


\section{BIBLIOGRAFIA}

[1] OLAZABAL-HERRERO, A., SENDINO, M., ARGANDA-CARRERAS, I. eta RODRIGUEZ, J.A. 2019. «WDR20 regulates shuttling of the USP12 deubiquitinase complex between the plasma membrane, cytoplasm and nucleus». European Journal ofCell Biology, 98, 12-26.

[2] KNOCKENHAUER, K.E. eta SCHWARTZ, T.U. 2016. «The Nuclear Pore Complex as a flexible and dynamic gate». Cell, 164, 1162-1171.

[3] SCHMIDT, H.B eta GÖRLICH, D. 2016. «Transport selectivity of nuclear pores, phase separation, and membraneless organelles». Trends in Biochemical Sciences, 41, 46-61.

[4] PEMBERTON, L.F. eta PASCHAL, B.M. 2005. «Mechanisms of receptormediated nuclear import and nuclear export». Traffic, 6, 187-198.

[5] TRAN, E.J., KING, M.C. eta CORBETT, A.H. 2014. «Macromolecular transport between the nucleus and the cytoplasm: advances in mechanism and emerging links to disease». Biochimica et Biophysica Acta, 1843, 27842795.

[6] CAUTAIN, B., HILL, R., DE PEDRO, N. eta LINK, W. 2015. «Components and regulation of nuclear transport processes». The FEBS Journal, 282, 445-462.

[7] BECK, M. eta HURT, E. 2017. «The nuclear pore complex: understanding its function through structural insight». Nature Reviews Molecular Cell Biology, 18, 73-89.

[8] ÇAĞATAY, T. eta CHOOK, Y.M. 2018. «Karyopherins in cancer». Current Opinion in Cell Biology, 52, 30-42.

[9] SONIAT, M. eta CHOOK, Y.M. 2015. «Nuclear localization signals for four distinct karyopherin- $\beta$ nuclear import systems». Biochemical Journal, $\mathbf{4 6 8}$, 353-362.

[10] SENDINO, M., OMAETXEBARRIA, M.J eta RODRIGUEZ, J.A. 2018. «Hitting a moving target: inhibition of the nuclear export receptor XPO1/ CRM1 as a therapeutic approach in cancer». Cancer Drug Resistance, 1, 139-163.

[11] KIM, H.J. eta TAYLOR, J.P. 2017. «Lost in transportation: Nucleocytoplasmic transport defects in ALS and other neurodegenerative diseases». Neuron, 96, 285-297.

[12] XU, D., FARMER, A., COLLETT, G., GRISHIN, N.V. eta CHOOK. Y.M. 2012. «Sequence and structural analyses of nuclear export signals in the NESdb database». Molecular Biology of the Cell, 23, 3677-3693.

[13] DONG, X., BISWAS, A. eta CHOOK, Y.M. 2009. «Structural basis for assembly and disassembly of the CRM1 nuclear export complex». Nature Structural \& Molecular Biology, 16, 558-560.

[14] GAMA-CARVALHO, M. eta CARMO-FONSECA, M. 2001. «The rules and roles of nucleocytoplasmic shuttling proteins». FEBS Letters, 498, 157 163. 
[15] CAUTAIN, B., HILL, R., DE PEDRO, N. eta LINK, W. 2015. «Components and regulation of nuclear transport processes». FEBS J, 282, 445-462.

[16] FUKUDA, M., ASANO, S., NAKAMURA, T., ADACHI, M., YOSHIDA, M., YANAGIDA, M. eta NISHIDA, E. 1997. «CRM1 is responsible for intracellular transport mediated by the nuclear export signal». Nature, 390, 308-311.

[17] FORNEROD, M., OHNO, M., YOSHIDA, M. eta MATTAJ, I.W. 1997. «CRM1 is an export receptor for leucine-rich nuclear export signals». Cell, 90, 1051-1060.

[18] STADE, K., FORD, C.S., GUTHRIE, C. eta WEIS, K. «Exportin 1 (Crm1p) is an essential nuclear export factor». Cell, 90, 1041-1050.

[19] OSSAREH-NAZARI, B., BACHELERIE, F. eta DARGEMONT, C. 1997. «Evidence for a role of CRM1 in signal-mediated nuclear protein export». Science, 278, 141-144.

[20] HAMAMOTO, T., UOZUMI, T. eta BEPPU, T. 1985. «Leptomycines A and B, new antifungal antibiotics III. mode of action of Leptomycin B on Schizosaccharomyces pombe». The Journal of Antibiotics, 38, 1573-1580.

[21] KUDO, N., WOLFF, B., SEKIMOTO, T., SCHREINER, E.P., YONEDA, Y., TANAGIDA, M., HORINOUCHI, S. eta YOSHIDA, M. 1998. «Leptomycin B inhibition of signal-mediated nuclear export by direct binding to CRM1». Experimental Cell Research, 242, 540-547.

[22] GARCÍA-SANTISTEBAN, I., ARREGI, I., ALONSO-MARIÑO, M., URBANEJA, M.A., GARCIA-VALLEJO, J.J., BAÑUELOS, S. eta RODRÍGUEZ, J.A. 2016. «A cellular reporter to evaluate CRM1 nuclear export activity: functional analysis of the cancer-related mutant E571K». Cellular and Molecular Life Sciences, 73, 4685-4699.

[23] GOULD, C.M., DIELLA, F., VIA, A., PUNTERVOLL, P., GEMÜND, C., CHABANIS-DAVIDSON, S., MICHAEL, S., SAYADI, A., BRYNE, J.C., CHICA, C., SEILER, M., DAVEY, N.E., HASLAM, N., WEATHERITT, R.J., BUDD, A., HUGHES, T., PAS, J., RYCHLEWSKI, L., TRAVÉ, G., AASLAND, R., HELMER-CITTERICH, M., LINDING, R. eta GIBSON, T.J. 2010. «ELM: the status of the 2010 eukaryotic linear motif resource». Nucleic Acids Research, 38, 167-180.

[24] LA COUR, T., KIEMER, L., MØLGAARD, A., GUPTA, R., SKRIVER, K. eta BRUNAK, S. 2004. "Analysis and prediction of leucine-rich nuclear export signals». Protein Engineering, Design \& Selection, 17, 527-536.

[25] FU, S.C., IMAI, K. eta HORTON, P. 2011. «Prediction of leucine-rich nuclear export signal containing proteins with NESsential». Nucleic Acids Research, 39, e111.

[26] PRIETO, G., FULLAONDO, A. eta RODRIGUEZ J.A. 2014. «Prediction of nuclear export signals using weighted regular expressions (Wregex)». Bioinformatics, 30, 1220-1227.

[27] HENDERSON, B.R. eta ELEFTHERIOU, A. 2000. «A comparison of the activity, sequence specificity, and CRM1-dependence of different nuclear export signals». Experimental Cell Research, 256, 213-224. 
Maria Sendino, Anne Olazabal-Herrero, José Antonio Rodriguez, Miren Josu Omaetxebarria

[28] KIRLI, K., KARACA, S., DEHNE, H.J., SAMWER, M., PAN, K.T., LENZ, C., URLAUB, H. eta GÖRLICH, D. 2015. «A deep proteomics perspective on CRM1-mediated nuclear export and nucleocytoplasmic partitioning». Elife, 4, e11466.

[29] KOMANDER, D., CLAGUE, M.J. ETA URBÉ, S. 2009. «Breaking the chains: structure and function of the deubiquitinases». Nature Reviews Molecular Cell Biology, 10, 550-563.

[30] RODRIGUEZ, J.A. 2014. «Interplay between nuclear transport and ubiquitin/SUMO modifications in the regulation of cancer-related proteins». Seminars in Cancer Biology, 27, 11-19.

[31] GARCIA-SANTISTEBAN, I., BAÑUELOS, S. eta RODRIGUEZ, J.A. 2012. «A global survey of CRM1-dependent nuclear export sequences in the human deubiquitinase family». Biochemical Journal, 441, 209-217.

[32] GANGULA, N.R. eta MADDIKA, S. 2013. «WD repeat protein WDR48 in complex with deubiquitinase USP12 suppresses Akt-dependent cell survival signalling by stabilizing $\mathrm{PH}$ domain leucine-rich repeat protein phosphatise 1 (PHLPP1)». The Journal of Biological Chemistry, 288, 34545-34554.

[33] LI, X., STEVENS, P.D., YANG, H., GULHATI, P., WANG, W., EVERS, B.M. eta GAO, T. 2013. «The deubiquitination enzyme USP46 functions as a tumor suppressor by controlling PHLPP-dependent attenuation of Akt signalling in colon cancer». Oncogene, 32, 471-478.

[34] SOWA, M.E., BENNETT, E.J., GYGI, S.P. eta HARPER, J.W. 2009. «Defining the human deubiquitinating enzyme interaction landscape». Cell, 138, 389-403.

[35] URBÉ, S., LIU, H., HAYES, S.D., HERIDE, C., RIGDEN, D.J. eta CLAGUE, M.J. 2012. «Systematic survey of deubiquitinase localization identifies USP21 as a regulator of centrosome and microtubule-associated functions». Molecular Biology of the Cell, 23, 1095-1103.

[36] BURSKA, U.L, HARLE, V.J., COFFEY, K., DARBY, S., RAMSEY, H., O’NEILL, D., LOGAN, I.R., GAUGHAN, L. eta ROBSON, C.N. 2013. «Deubiquitinating enzyme Usp12 is a novel co-activator of the androgen receptor». The Journal of Biological Chemistry, 288, 32641-32650.

[37] LEHOUX, M., GAGNON, D. eta ARCHAMBAULT, J. 2014. «E1-mediated recruitment of a UAF1-USP deubiquitinase complex facilitates human papillomavirus DNA replication». Journal of Virology, 88, 8545-8555.

[38] OLAZABAL-HERRERO, A., GARCÍA-SANTISTEBAN, I. eta RODRIGUEZ, J.A. 2015. «Structure-function analysis of USP1: insights into the role of Ser313 phosphorylation site and the effect of cancer-associated mutations on autocleavage». Molecular Cancer, 14.

[39] JOO, H.Y., JONES, A., YANG, C., ZHAI, L., SMITH, IV A.D., ZHANG, Z., CHANDRASEKHARAN, M.B., SUN, Z.W., RENFROW, M.B., WANG, Y., CHANG, C. eta WANG, H. 2011. «Regulation of histone H2A and H2B deubiquitination and Xenopus development by USP12 and USP46». The Journal of Biological Chemistry, 286, 7190-7201. 
[40] JAHAN, A.S., LESTRA, M., SWEE, L.K., FAN, Y., LAMERS, M.M. TAFESSE, F.G., THEILE, C.S., SPOONER, E., BRUZZONE, R., PLOEGH, H. L. eta SANYAL, S. 2016. «Usp12 stabilizes the T-cell receptor complex at the cell surface during signaling». Proceedings of the National Academy of Sciences of the United States of America, 113, E705-714.

[41] KOURANTI, I., MCLEAN, J.R., FEOKTISTIVA, A., LIANG, P., JOHNSON, A.E., ROBERTS-GALBRAITH, R.H. eta GOULD, K.L. 2010. «A global census of fission yeast deubiquitinating enzyme localization and interaction networks reveals distinct compartmentalization profiles and overlapping functions in endocytosis and polarity». PLOS Biology, 8, e1000471.

[42] SANYAL, S., 2016. «Reply to Rodriguez: mechanism of nuclear-cytosol shuttling of Usp12». Proceedings of the National Academy of Sciences of the United States of America, 113, E3317-3318.

[43] LI, H., LIM, K.S., HINDS, T.R., JO, U., MAO, H., WELLER, C.E., SUN, J., CHATTERJEE, C., D'ANDREA, A.D. eta ZHENG, N. 2016. «Allosteric activation of ubiquitin-specific proteases by $\beta$-propeller proteins UAF1 and WDR20». Molecular Cell, 63, 249-260. 